\section{Functional Rectal Carcinoid Tumour and Ocular Myopathy}

\author{
M. AHMED, H. IRFAN
}

British Medical Fournal, 1973, 2, 699

We report a patient suffering from flushing and abdominal symptoms, who was found to have a rectal carcinoid tumour and multiple liver and peritoneal metastases. Biochemical investigations confirmed that the rectal carcinoid tumour was secreting pharmacologically active substances, although it is commonly accepted that rectal carcinoids are non-functioning. The patient also had an ocular myopathy, which was found to be familial.

\section{Case Report}

A 73-year-old man presented with a history of anorexia, diarrhoea, and loss of weight for abour 16 years, but rather worse during the last three years. Motions were passed about three to four times a day, and the stool was watery, with no blood or mucous. He had abdominal discomfort from wind and also complained of increased lacrimation and salivation. Flushing of the face, hands, legs, and thighs had occured for about 19 years. Originally it oocured after meals, but for the last 10 years it had become more permanent.

He had double vision, difficulty in reading, and difficulty in closing his eyes, starting some 20 years ago. These symptoms progressed slowly until he developed complete external ophthalmoplegia. In 1960 it was confirmed that he had ocular myopathy. In 1961 he had dizziness and fainting attacks, which were thought to be due to a minor cerebral thrombosis, from which he recovered completely. His only sister has had ocular myopathy for the past 15 years. She was simultaneously investigated at the Midland Centre for Neurosurgey.

On examination he was of average build, intelligent, pleasant, and humorous. His face was flushed and cyanosed. He had increased pigmentation of hands, forearms, face, and neck, and he had scaly vesicular dermatitis diagnosed as cheiropompholyx in the hands. He had complete external ophthalmoplegia, with drooping of both eyelids. There was no oedema, jaundice, or lymphadenopathy. The thyroid gland was normal. Pulse was 80 per minute, regular, blood pressure $160 / 90 \mathrm{~mm} \mathrm{Hg}$. Jugular venous pressure was not raised, the heart was not clinically enlarged, and there was no murmur. The chest was clear. The abdomen was soft, the liver was enlarged about 3 in., smooth and non-tender, the spleen was not palpable. No other masses were palpable in the abdomen. Rectal examination showed a large, fixed mass in the right anterior aspect. On examination of the central nervous system the fundi were normal, and cranial nerves were normal. No abnormality was detected in the rost of the central nervous system.

\section{INVESTIGATIONS}

Routine blood tests, chest $x$-ray, barium enema, and barium meal examinations were all within normal limits. Twenty-four hour urine 5-hydroxy indole excretion tests showed $29 \mathrm{mg}, 34 \mathrm{mg}$, and 23.8 $\mathrm{mg}$ on three different days (normal 2 to $13 \mathrm{mg}$ ). Serum 5-hydroxytryptamine was $2.5 \mu \mathrm{g} / \mathrm{ml}$.

TREATMENT AND PROGRESS

At laparotomy a lange neoplastic mass around the rectum was found, with multiple secondaries in the mesentery and the liver, but

\section{Whitley Hospital, Coventry, Warwickshire}

M. AHMED, M.B., M.R.C.P., Senior Registrar in Geriatrics

Burton Road Hospital, Dudley, Worcestershire

H. IRFAN, M.B., M.R.C.P., Consultant Physician

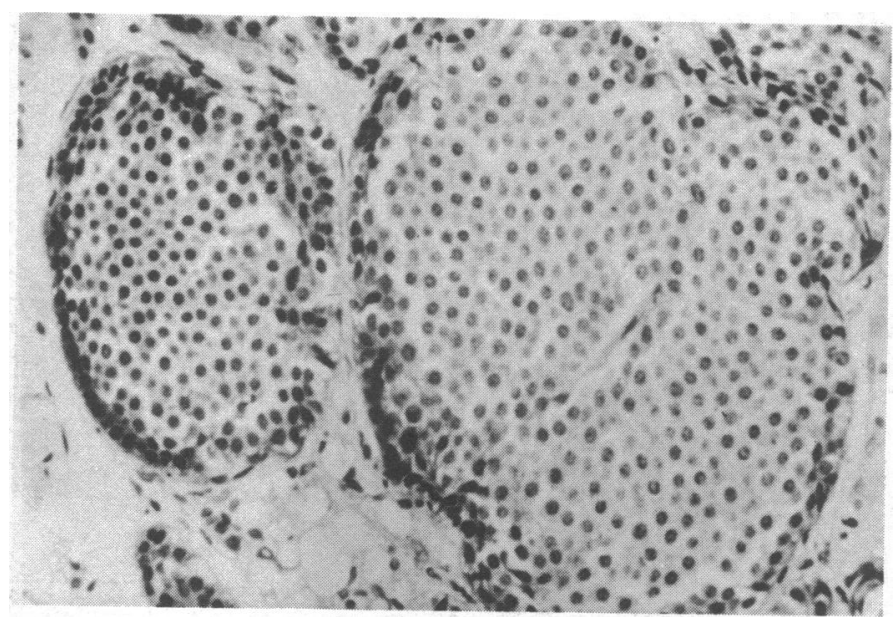

Histological appearances of rectal carcinoid tumour.

the whole of the small intestine, appendix, and the rest of the colon was normal. A biopsy specimen of the mesenteric secondaries was taken, and histological examination confirmed the presence of carcinoid tumour (fig.). He was treated with an antiserotonin agent, cyproheptadine.

\section{Comment}

Carcinoid tumours were first described by Merling in 1808 (Cecil and Loeb, 1971). The term carcinoid was introduced by Oberdofer (1907) to distinguish this tumour from carcinoma. Seven years later it was shown that the tumour cells contained cytoplasmic granules that reduce silver salts. Thorson and his associates (1952) noticed the association of pulmonary stenosis, tricuspid incompetence, and a peculiar type of intermittent cyanosis in a young man who at necropsy was found to have argentaffinoma of the small intestine, with extensive abdominal metastases.

Typical functioning malignant carcinoid develops from a small primary of the distal third of the ileum. Other sites of origin include the small bowel elsewhere, Meckel's diverticulum, stomach, colon, bronchus, bile ducts, pancreas, and ovary. Appendixial carcinoids rarely metastasize, and rectal carcinoids are non-functioning. In one case Gabriel and Morson (1956) found that cells of rectal carcinoid did not contain "cytoplasmic granules," and 5-hydroxyindole excretion in urine was normal. Peskin and Orloff (1959) reviewed 25 cases of rectal carcinoid, $40 \%$ of which were malignant, and although in six cases extensive hepatic metastasis occurred, signs of malignant carcinoid syndrome due to excessive secretion of serotonin were not detected. So far as is known, this is the first case of rectal carcinoid tumour shown to be secreting pharmacologically active substances to produce carcinoid syndrome.

We would like to thank Mr. H. Kramer for performing the laparotomy and biopsy, and Dr. S. P. Way for taking a special interest in the histology.

Requests for reprints should be addressed to: Dr. M. Ahmed, Senior Registrar (Geriatrics), Whitley Hospital, London Road, Coventry, Warwickshire.

\section{References}

Cecil and Loeb (1971). Texbook of Medicine, ed. P. B. Beeson and W. McDermott, 13th edn., p. 1251. Philadelphia, Saunders.

Gabriel, W. B., and Morson, B. C. (1956). Proceedings of the Royal Society of Medicine, 49, 472.

Oberdofer, S., and Frankfurt, Z. (1907). Pathology, 1, 426.

Peskin, G. W., and Orloff, M. J. (1959). Surgery, Gymecology and Obstetrics, 109,673 .

Thorson, A., Biörek, G., and Axen, O. (1952). American Heart Gournal, 44, 143. 